www.nature.com/jhg

\title{
Combined microdeletions and CHD7 mutation causing severe CHARGE/DiGeorge syndrome: clinical presentation and molecular investigation by array-CGH
}

\begin{abstract}
Marios Kaliakatsos $^{1,5}$, Aristeidis Giannakopoulos ${ }^{1,5}$, Helena Fryssira ${ }^{2}$, Maria Kanariou ${ }^{3}$, Anna-Venetia Skiathitou ${ }^{1}$, Tania Siahanidou ${ }^{1}$, Krinio Giannikou ${ }^{2}$, Periklis Makrythanasis ${ }^{2,6}$, Emmanuel Kanavakis ${ }^{2,4}$ and Maria Tzetis ${ }^{2}$

Phenotypic variation in CHARGE syndrome remains unexplained. A subcategory of CHARGE patients show overlapping phenotypic characteristics with DiGeorge syndrome (thymic hypo/aplasia, hypocalcemia, T-cell immunodeficiency). Very few have been tested or reported to carry a mutation of the CHD7 (chromodomain helicase DNA-binding domain) gene detected in two-thirds of CHARGE patients. In an attempt to explore the genetic background of a severe CHARGE/DiGeorge phenotype, we performed comparative genomic array hybridization in an infant carrier of a CHD7 mutation. The high-resolution comparative genomic array hybridization revealed interesting findings, including a deletion distal to the DiGeorge region and disruptions in other chromosomal regions of genes implicated in immunological and other functions possibly contributing to the patient's severe phenotype and early death.
\end{abstract}

Journal of Human Genetics (2010) 55, 761-763; doi:10.1038/jhg.2010.95; published online 5 August 2010

Keywords: aCGH; CHARGE syndrome; DiGeorge syndrome; T-cell immunodeficiency

Haploinsufficiency of the CHD7 (chromodomain helicase DNAbinding domain) gene was recently identified as a cause of CHARGE syndrome, ${ }^{1}$ with about two-thirds of patients having mutations in the CHD7 gene. ${ }^{2,3}$ A thorough literature review documented 17 patients with CHARGE and variable T-cell immunodeficiency, ${ }^{4}$ with some cases having overlapping characteristics with DiGeorge syndrome, which in its classical presentation combines conotruncal heart defects, hypocalcemia and thymic hypoplasia. ${ }^{4,5}$ No correlation between genotype and phenotype has been noted in CHARGE syndrome as shown from familial cases or large cohorts in which a CHD7 mutation was found. ${ }^{2,3,6-8}$ The role of possible modifying genetic or epigenetic factors in the phenotypic expression of T-cell immunodeficiency in CHARGE patients remains to be deciphered.

We report on a patient with overlapping characteristics of CHARGE and DiGeorge syndromes. The male proband, weighing $2600 \mathrm{~g}$, was delivered by cesarean section at $39 \frac{4}{7}$ weeks' gestation. His parents (28-years-old primiparous mother and 32-years-old father) were both healthy and unrelated. Because of increased nuchal translucency, amniocentesis was performed and was normal. Congenital anomalies were noted immediately after birth (Table 1 ). On the 10th day he developed persistent hypocalcemia, requiring calcium and 1- $\alpha$ vitamin D supplementation.

Generalized clonic seizures, proving refractory to different combinations of antiepileptic drugs, appeared on the 13th day and brain magnetic resonance imaging carried out on the 15th day showed no specific findings, while absence of thymus was noted by ultrasound. Microlaryngoscopy documented severe laryngomalacia causing repeated desaturation episodes, leading to a tracheotomy at the age of 1.5 months. A generalized erythroderma with a florid, scaly, icthyotic macular rash resembling that in Omenn's syndrome appeared at 2.5 months of age. He also developed total alopecia.

The infant, although under intravenous immunoglobulin replacement therapy and chemoprophylaxis, suffered from recurrent infections of the respiratory tract with frequent concurrent septicemia requiring aggressive antibiotic therapy. His respiratory function deteriorated and necessitated gradual increases of oxygen supply. Finally, the patient succumbed to respiratory insufficiency during the course of a new infection. No autopsy was performed because of parental refusal.

\footnotetext{
${ }^{1}$ Neonatal Unit, First Department of Pediatrics, Medical School, University of Athens, Athens, Greece; ${ }^{2}$ Department of Medical Genetics, Medical School, University of Athens, Athens, Greece; ${ }^{3}$ Department of Immunology and Histocompatibility, 'Aghia Sophia' Children's Hospital, Athens, Greece and ${ }^{2}$ Research Institute for the Study of Genetic and Malignant Disorders in Childhood, 'Aghia Sophia' Children's Hospital, Athens, Greece

${ }^{5}$ These authors contributed equally to this work.

${ }^{6}$ Current Address: Service of Genetic Medicine, University Hospitals of Geneva, Geneva, Switzerland.

Correspondence: Dr M Tzetis, Department of Medical Genetics, Medical School, University of Athens, Thivon \& Levadias, Athens 11527 , Greece.

E-mail: mtzetis@med.uoa.gr
}

Received 16 May 2010; revised 22 June 2010; accepted 7 July 2010; published online 5 August 2010 
Detailed testing to explore the proband's immune status ${ }^{9}$ (Supplementary Table 1) revealed low number of T but normal B and natural killer lymphocyte subpopulations. There was no proliferative response of $\mathrm{T}$ lymphocytes to mitogens, and the white blood cell count showed eosinophilia (19\%). At the age of 7 months, a second immune investigation noted marked lymphocytosis with increased $\mathrm{T}$ lymphocyte numbers together with low IgG and elevated IgE levels (Supplementary Table 1). T-cell receptor $\mathrm{V} \beta$ studies showed marked oligoclonality of $\mathrm{T}$ lymphocytes with $\mathrm{V} \beta 3$ of $26.2 \%$ (normal range $0.5-15.7 \%)$. There was no evidence of maternal engraftment by molecular studies.

Sequence analysis of the CHD7 gene revealed a heterozygous pathogenic frameshift mutation in exon 16, c.3838_3851del (p.Phe1280fs). ${ }^{3}$ The link of $C H D 7$ mutations with $\mathrm{T}-\mathrm{B}+$ severe combined immunodeficiency, and features of Omenn's syndrome has been confirmed in our patient and has been described in CHARGE syndrome. ${ }^{10}$

Table 1 Major clinical characteristics of the patient

\begin{tabular}{|c|c|}
\hline Congenital anomalies/dysmorphisms & Other abnormalities \\
\hline Arched eyebrows & Bilateral choroidal and disc coloboma \\
\hline Micropthalmia & Bicuspid aortic valve \\
\hline Micrognathia & Patent nasal choanae \\
\hline Unilateral facial nerve palsy on the left & Absence of the semicircular canals \\
\hline Low-set ears with abnormal pinnae & Absence of thymus \\
\hline (cup-shaped) & Severe laryngomalacia \\
\hline \multicolumn{2}{|l|}{ Broad nasal bridge } \\
\hline \multicolumn{2}{|l|}{ Smooth philtum } \\
\hline \multicolumn{2}{|l|}{ Flattened midface } \\
\hline \multicolumn{2}{|l|}{ Short and webbed neck } \\
\hline \multicolumn{2}{|l|}{ Pectus excavatum, } \\
\hline \multicolumn{2}{|l|}{ Wide-spaced nipples } \\
\hline \multicolumn{2}{|l|}{ Abnormal palmar creases } \\
\hline \multicolumn{2}{|l|}{ Right unilateral cryptorchidism } \\
\hline \multicolumn{2}{|l|}{ Hypoplastic scrotum, micropenis } \\
\hline Syndactyly of the 2 nd-3rd toes bilaterally & \\
\hline
\end{tabular}

To further characterize the infant's severe phenotype, a comparative genomic array hybridization was performed (Agilent Technologies, Santa Clara, CA, USA), ${ }^{11}$ revealing interesting findings (Table 2). The de novo nature of the $15 \mathrm{q} 22.31$ deletion $(0.077 \mathrm{Mb})$ with absence of known copy number variations makes it potentially pathogenic. CILP-1 gene functions as an insulin-like growth factor 1 antagonist, especially in chondrocytes, ${ }^{12}$ but we cannot speculate how it affects the proband's pathogenesis.

The second de novo Xp22.12 (0.052 Mb) microdeletion with no known copy number variations contains the $S H 3 K B P 1$ gene. ${ }^{13}$ SH3KBP1 is a multiadaptor protein involved in different cellular functions, including downregulation of activated receptor tyrosine kinases, survival of neuronal cells and enhancement of tumor necrosis factor-mediated apoptotic cell death. SH3KBP1 also controls postmembrane events, such as targeting receptors for degradation and regulation of gene transcription, possibly by binding to multiple adaptor proteins. ${ }^{14}$ Similar to the $C H D 7, S H 3 K B P 1$ appears to be involved through different networks and gene complexes on essential cell functions, and therefore may have contributed to the complex phenotype.

Microdeletion $7 \mathrm{q} 21.11(0.021 \mathrm{Mb})$ starts $15 \mathrm{bp}$ into intron 9 of the MAGI2 gene, and could therefore cause aberrant splicing of the gene. MAGI2 is telomeric to the Williams-Beuren syndrome (WBS; OMIM\# 194050) gene region (7q11.23). Findings on Williams-Beuren syndrome patients have implicated disruption of the MAGI2 gene as a locus for infantile spasm. ${ }^{15}$ Disruption of the MAGI2 gene probably contributed to the infant's generalized clonic seizures, appearing on day 13 and refractory to different combinations of anti-epileptic drugs.

A paternally inherited aberration in 8 p $22(0.074 \mathrm{Mb})$ included partial deletion of MSR1. A recent study strongly supports that genetic variants expressing different levels of MSR1 show differing abilities to clear apoptotic cells, and eventually lead to the hyper-inflammatory stage characteristic of septic shock. ${ }^{16}$ The loss of MSR1 may not have been responsible for the infant's initial phenotype, but could have contributed to the recurrent infections of the respiratory tract with frequent concurrent septicemia, and was probably a major cause of the infant's early death.

Table 2 aCGH results

\begin{tabular}{|c|c|c|c|}
\hline Abberation $^{a}$ & Gene $^{\mathrm{b}}$ & Inheritance & $\begin{array}{l}\text { Presence of common } \\
\text { CNVs/log } 2 \text { ratio of probes }\end{array}$ \\
\hline DEL2q35, $145.3 \mathrm{~kb}$ & IGFBP5: insulin-like growth factor binding protein 5 & Paternal & No CNVs/-0.378 \\
\hline Nucleotides: 217072704-217217982 & RPL37A: ribosomal protein, component of 60 S subunit & & \\
\hline $\begin{array}{l}\text { DEL 7q21.11; } 20.55 \mathrm{~kb} \\
\text { Nucleotides: } 77703312-77723858\end{array}$ & MAGI2: membrane-associated guanylate kinase inverted-2 gene & $\begin{array}{l}\text { Paternal and } \\
\text { maternal }\end{array}$ & No CNVs/-1.06 \\
\hline $\begin{array}{l}\text { Del 8p22; } 74.33 \mathrm{~kb} \\
\text { Nucleotides: } 15996382-16070713\end{array}$ & MSR 1: macrophage scavenger receptor 1 & Paternal & Yes/-0.657 \\
\hline $\begin{array}{l}\text { DEL 15q22.31; } 76.62 \mathrm{~kb} ; \\
\text { Nucleotides: } 63280700-63357315\end{array}$ & CILP: cartilage intermediate layer protein & De novo & No CNVs/-0.626 \\
\hline DEL 20q13.2; $31.31 \mathrm{~kb}$ & MATN4: Matrillin 4 & Paternal & No CNVs/-0.93 \\
\hline Nucleotides: $43343828-43375135$ & $\begin{array}{l}R B P J L \text { : recombination signal binding protein for immunoglobulin } \\
\text { kappa J region-like }\end{array}$ & & \\
\hline DEL 22q11.23; 249.5 kb; & IGLL3: immunoglobulin lambda-like polypeptide 3 & Paternal & Yes/-0.454 \\
\hline Nucleotides: 23984069-24233543 & $\angle R P 5 L$ : low-density receptor-related lipoprotein & & \\
\hline $\begin{array}{l}\text { DEL Xp22.12; } 52.84 \mathrm{~kb} ; \\
\text { Nucleotides: } 19733082-19785919\end{array}$ & SH3KBP1: SH3-domain kinase binding protein 1 & De novo & No CNVs/-0.953 \\
\hline
\end{tabular}

Abbreviations: aCGH, comparative genomic array hybridization; CNVs, copy number variations.

aAgilent $244 \mathrm{~K}$ arrays with average resolution $6 \mathrm{~kb}$.

bUCSC database (http://genome.ucsc.edu/), UCSC. 
Another paternally inherited deletion 20q13.2 (0.031 Mb), lacking known copy number variations, contains two genes: MATN4 and RBPJL. RBPJL has been implicated in the pancreatic acinar development through its association with a trimeric complex (PTF1-J). ${ }^{17}$ The patient, however, was not investigated for pancreatic development and function.

Finally, microdeletion 22q11.23 located at a region distally to the one involved in DiGeorge and velocardiofacial syndromes is of interest because of its proximity to a recurrent genomic disorder, clinically distinct from the two aforementioned syndromes with clinical features similar to our proband, such as facial dysmorphism (arched eyebrows, flattened midface and smooth philtrum), a bicuspid aortic valve, and developmental and growth delay. ${ }^{18}$ This more distal non-overlapping deletion probably contributes to the phenotype not only through the two genes: IGLL3 and $L P R 5 L,{ }^{19}$ but also through gene expression in the general area of the DiGeorge/velocardiofacial region by position effect possibly eliminating locus control regions from their targeted genes leading to this complex phenotype. ${ }^{20}$

The array comparative genomic hybridization method, carried out for the first time on a CHD7 mutation carrier with severe CHARGE/ DiGeorge and Ommen like-phenotypic overlap, detects genomic disruptions at regions that contain genes involved in immune and related functions that could also explain the mechanism of phenotypic discrepancies in CHARGE patients.

\section{ACKNOWLEDGEMENTS}

We are grateful to Dr Lies H Hoefsloot and her collaborators (DNA Diagnostics Department of Human Genetics, Radboud University Nijmegen Medical Centre, Nijmegen, The Netherlands) for carrying out whole $\mathrm{CHD} 7$ gene sequencing analysis, as well as to Dr Marianna Tzanoudaki and Cleopatra Spanou, MSc (Department of Immunology and Histocompatibility, 'Aghia Sophia' Children's Hospital, Athens, Greece) for immunological analysis. K Giannikou is supported by a scholarship provided by the Alexander Onassis Foundation. We also wish to express our gratitude to the parents for their consent to report this case.

1 Vissers, L. E., van Ravenswaaij, C. M., Admiraal, R., Hurst, J. A., de Vries, B. B., Janssen, I. M. et al. Mutations in a new member of the chromodomain gene family cause CHARGE syndrome. Nat. Genet. 36, 955-957 (2004).

2 Lalani, S. R., Safiullah, A. M., Fernbach, S. D., Harutyunyan, K. G., Thaller, C., Peterson, L. E. et al. Spectrum of CHD7 mutations in 110 individuals with CHARGE syndrome and genotype-phenotype correlation. Am. J. Hum. Genet. 78, 303-314 (2006).

3 Wincent, J., Holmberg E., Stromland, K., Soller, M., Mirzaei, L., Djureinovic, T. et al. CHD7 mutation spectrum in 28 Swedish patients diagnosed with CHARGE syndrome. Clin. Genet. 74, 31-38 (2008).

4 Writzl, K., Cale, C. M., Pierce, C. M., Wilson, L. C. \& Hennekam, R. C. Immunological abnormalities in CHARGE syndrome. Eur. J. Med. Genet. 50, 338-345 (2007)

5 de Lonlay-Debeney, P., Cormier-Daire, V., Amiel, J., Abadie, V., Odent, S., Paupe, A. et al. Features of DiGeorge syndrome and CHARGE association in five patients. J. Med. Genet. 34, 986-989 (1997).

6 Aramaki, M., Udaka, T., Kosaki, R., Makita, Y., Okamoto, N., Yoshihashi, H. et al. Phenotypic spectrum of CHARGE syndrome with CHD7 mutations. J. Pediatr. 148, 410-414 (2006).

7 Delahaye, A., Sznajer, Y., Lyonnet, S., Elmaleh-Berges, M., Delpierre, I., Audollent, S. et al. Familial CHARGE syndrome because of CHD7 mutation: clinical intra- and interfamilial variability. Clin. Genet. 72, 112-121 (2000).

8 Verloes, A. Updated diagnostic criteria for CHARGE syndrome: a proposal. Am. J. Med. Genet. A 133A, 306-308 (2005).

9 Cao, K., Chopek, M. \& Fernandez-Vina, M. A. High and intermediate resolution DNA typing systems for class I HLA-A, B, C genes by hybridization with sequence-specific oligonucleotide probes (SSOP). Rev. Immunogenet. 1, 177-208 (1999).

10 Gennery, A. R., Slatter, M. A., Rice, J., Hoefsloot, L. H., Barge, D., McLean-Tooke, A. et al. Mutations in CHD7 in patients with CHARGE syndrome cause T-B + natural killer cell + severe combined immune deficiency and may cause Omenn-like syndrome. Clin. Exp. Immunol. 153, 75-80 (2008).

11 Kitsiou-Tzeli, S., Tzetis, M., Sofocleous, C., Vrettou, C., Xaidara, A., Giannikou, K. et al. De novo interstitial duplication of the 15q11.2-q14 PWS/AS region of maternal origin: clinical description, array CGH analysis, and review of the literature. Am. J. Med. Genet. A (e-pub ahead of print 23 June 2010) (2010).

12 Virtanen, I. M., Song, Y. Q., Cheung, K. M., Ala-Kokko, L., Karppinen, J., Ho, D. W. et al. Phenotypic and population differences in the association between CILP and lumbar disc disease. J. Med. Genet. 44, 285-288 (2007).

13 Narita, T., Amano, F., Yoshizaki, K., Nishimoto, N., Nishimura, T., Tajima, T. et al. Assignment of SH3KBP1 to human chromosome band Xp22.1-p21.3 by in situ hybridization. Cytogenet. Cell Genet. 93, 133-134 (2001).

14 Soubeyran, P., Kowanetz, K., Szymkiewicz, I., Langdon, W. Y. \& Dikic, I. CbI-CIN85endophilin complex mediates ligand-induced downregulation of EGF receptors. Nature 416, 183-187 (2002).

15 Marshall, C. R., Edwin, J., Young, E. J., Pani, A. M., Freckmann, M. L., Lacassie, Y. et al. Infantile spasms is associated with deletion of the MAGI2 gene on chromosome 7q11.23-q21.11. Am. J. Hum. Genet. 83, 106-111 (2008).

16 Fortin, A., Penman, M., Stevenson, M. M., Krieger, M. \& Gros, P. Identification and characterization of naturally occurring variants of the macrophage scavenger receptor (SR-A). Mamm. Genome 11, 779-785 (2000).

17 Masui, T., Swift, H. G., Hale, M. A., Meredith, D. M., Johnson, J. E. \& MacDonald, R. J. Transcriptional autoregulation controls pancreatic Ptfla expression during development and adulthood. Mol. Cell. Biol. 28, 5458-5468 (2008).

18 Ben-Shachar, S., Ou, Z., Shaw, C. A., Belmont, J. W., Patel, M. S., Hummel, M. et al. 22q11.2 distal deletion: a recurrent genomic disorder distinct from DiGeorge syndrome and velocardiofacial syndrome. Am. J. Hum. Genet. 82, 214-221 (2008).

19 Bauer, T. R. Jr, McDermid, H. E., Budarf, M. L., Van Keuren, M. L. \& Blomberg, B. B. Physical location of the human immunoglobulin lambda-like genes, 14.1, 16.1, and 16.2. Immunogenetics 38, 387-399 (1993).

20 Henrichsen, C. N., Chaignat, E. \& Reymond, A. Copy number variants, diseases and gene expression. Hum. Mol. Genet. 18, R1-R8 (2009).

Supplementary Information accompanies the paper on Journal of Human Genetics website (http://www.nature.com/jhg) 